\title{
Hormone induced recipients for embryo transfer in mice
}

\author{
Yeonmi Lee ${ }^{1,2}$ and Eunju Kang ${ }^{1,2, *}$ \\ ${ }^{1}$ Department of Biomedical Science, College of Life Science, CHA University, Seongnam 13488, Korea \\ ${ }^{2}$ Center for Embryo and Stem Cell Research, CHA Advanced Research Institute, CHA University, Seongnam 13488, Korea
}

Received November 3, 2021

Revised December 8, 2021

Accepted December 9, 2021

\section{*Correspondence}

Eunju Kang

E-mail: ekang@cha.ac.kr

Author's Position and Orcid no. Lee $\mathrm{Y}$, Senior research scientist, https://orcid.org/0000-0003-4407-7731

Kang E, Asssociate professor,

https://orcid.org/0000-0002-7240-7868

\begin{abstract}
Embryo transfer (ET) in the animal is an important procedure to generate genetically engineered animals and conserve genetic resources. For ET experiments in mice, pseudopregnant recipients are usually prepared with proestrus stage of females and vasectomized males. However, this conventional method is inefficient because the size of female colonies should be large to select only the proestrus stage in the estrous cycle and the surgical procedures are required to generate vasectomized males. In this study, we established a simple and efficient protocol to prepare ET recipients using the estrous synchronization with hormone injection and the mating with wild male mice. The delivery rate of ET recipients tended to be increased with estrous synchronization using hormone injection (100\%) compared to the conventional method (71\%). Further, natural pregnancy of the recipients, induced by mating with a wild male, significantly enhanced the birth rate of ET offspring than the conventional method (33\% vs. 13\%). Based on the results, we concluded that our new protocol using hormone injection to ET recipients and mating with wild males could be more efficient and simpler compared to the conventional method.
\end{abstract}

Keywords: embryo transfer, estrous synchronization, mouse, recipient

\section{INTRODUCTION}

Assisted reproductive technologies (ARTs) have applications in a variety of fields including human clinics and basic science research (Mochida, 2020). In animals such as mice, ART is important for the conservation of genetic resources and the generation of genetically engineered animals (Hasegawa et al., 2017). Many ARTs have been developed, such as cryopreservation of sperm and embryos, superovulation, in vitro fertilization (IVF), embryo culture, and embryo transfer (ET) (Ha et al., 2013; Lee et al, 2015; Hasegawa et al., 2017; Lee et al., 2018; Barsuren et al., 2019; Chio et al., 2019; Kim and Park, 2019; Jung et al., 2020). The success of several ARTs such as cryo- preservation or IVF and the production of genetically engineered mice is dependent upon the ability of successful pregnancy after ET, therefore ET is an indispensable related to ART in mice (Lamas et al., 2020). Many factors could affect successful pregnancy after ET, such as age or weight of the recipients, pseudopregnancy of recipients, the type of anesthetic and analgesic, genetic backgrounds of the embryo and recipient strains, embryo stage and quality, the number of transferred embryos, the genetic modifications of embryos, and the surgical technique (Bradford, 1979; Ertzeid and Storeng, 2001; Mahabir et al., 2018; Lamas et al., 2020).

For conventional ET procedures, the preparation of pseudopregnant recipients is inefficient. Females at the 
proestrus stage are selected by visual observation of the vagina. The estrous cycle in mice is typically 4-5 days, therefore, it is required to keep at least 4-5 times the number of females than is actually used for ET (Hasegawa et al., 2017). Further, selected females were mated with vasectomized males, which were generated by surgical procedures (Byers et al., 2012). To reduce the size of female stocks for recipients, estrous synchronization was attempted by hormone injection (Hasegawa et al., 2017). Progesterone-treated females were paired with vasectomized males and ET efficiency was comparable to conventional ET procedures (Hasegawa et al., 2017). Even the size of the female colony could be reduced by hormone injection, however, vasectomized males were still required for this method. Vasectomized males are commonly used to make pseudopregnant recipients and the surgery for generating those mice should be accompanied by pain and discomfort (Preece et al., 2021). Further, surgery operators should be trained. Recently genetically modified mouse strains with a sterility phenotype were used instead of vasectomized mice, which provide a non-surgical replacement (Preece et al., 2021). However, these genetically sterile mice are not commonly available in general laboratories.

In this study, we used wild male mice to prepare ET recipients and examine the ET efficiency compared to the conventional method using vasectomized mice. We also used hormone injection for estrous synchronization of ET recipients.

\section{MATERIALS AND METHODS}

\section{Animals}

B6D2F1 (C57BL/6N female $\times$ DBA2 male) female and male mice (8 9-week-old, Charles River) were used for the production of blastocyst by in vitro fertilization (IVF). ICR female mice (10 12-week-old, Charles River) were used as recipients, and ICR wild or vasectomized male was mated with ICR female for preparation of pseudopregnant and pregnant recipients for embryo transfer. All animal maintenance and experimental procedures were performed following the guidelines of CHA University. The animal protocols were reviewed and approved by the Institutional Animal Care and Use Committee (IACUC No.210035) of CHA University.

\section{Experimental design}

Before devising new protocols for the production of the recipient for ET in this study, we set up the conventional method for the preparation of pseudopregnant recipients (Fig. 1). ICR female recipient mice were mated with vasectomized male mice overnight and checked plug the next morning. Plug positive recipients were used for ET. We then investigated new methods for the preparation of recipients for ET (Fig. 1). For the hormone group, ICR female recipient mice were injected PMSG, followed by hCG $48 \mathrm{~h}$ later. Some hormone-injected recipients were mated with wild ICR males overnight and checked plug following morning, as hormone + pairing group. Only plug-positive females were used for ET. The pups, generated by natu-

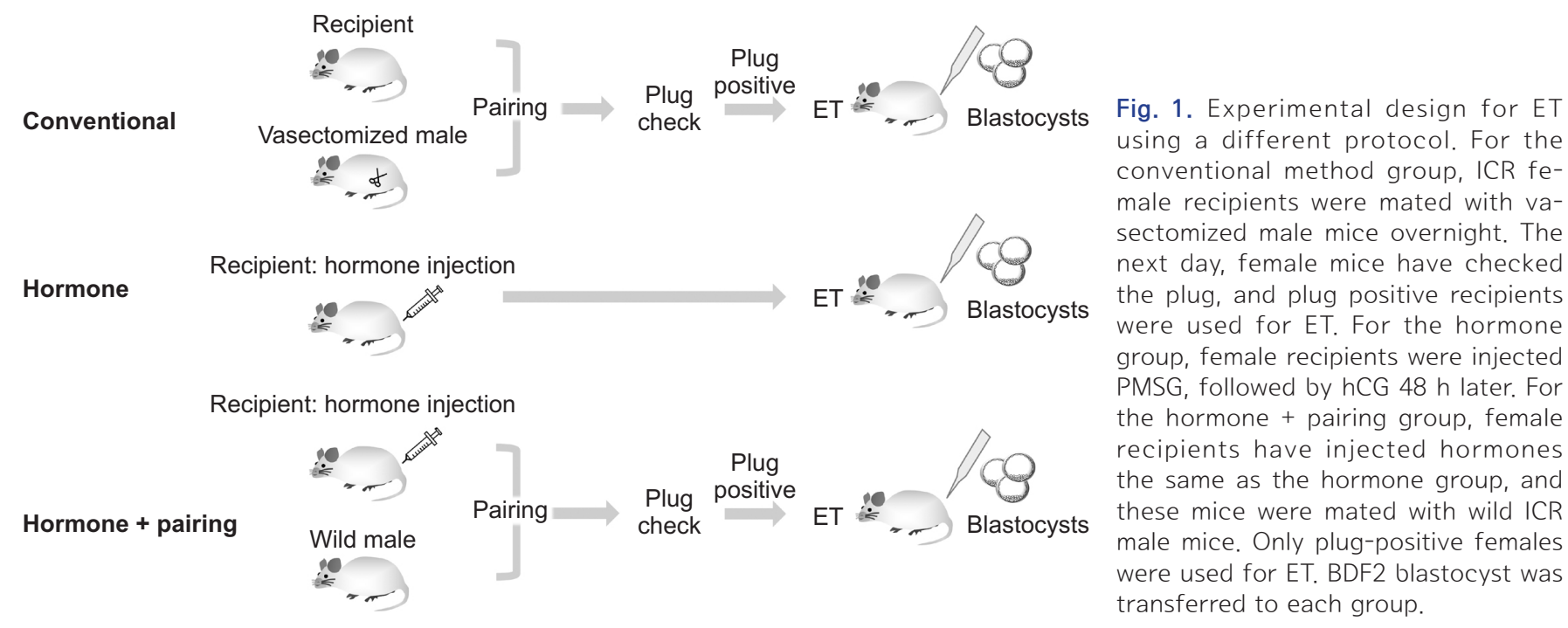


ral mating with ICR female recipients and males, should show white coat color. While ET pups were developed from BDF2 blastocysts and should have different coat colors such as black or brown, which could be distinguishable to ICR pups.

\section{MIl oocytes collection}

The experiment was performed according to the previously described methods (So et al., 2020). Female BDF1 mice were super-ovulated with 5 international units (IU) pregnant mare's serum gonadotropin (PMSG), followed by 5 IU human chorionic gonadotropin (hCG) 48 h later. MII oocytes were collected from the excised oviducts 13$16 \mathrm{~h}$ after hCG injection and cumulus cells were denuded with FHM medium containing 0.1\% hyaluronidase (SigmaAldrich). The denuded oocytes were kept in KSOM (Merck) before IVF under $5 \% \mathrm{CO}_{2}$ at $37^{\circ} \mathrm{C}$ in a humidified incubator.

\section{IVF and embryo culture}

The epididymis was transferred to Human Tubal Fluid (HTF) drop (Merck) and cut to make the sperm out. The sperms released from the epididymis in HTF drop were incubated under $5 \% \mathrm{CO}_{2}$ at $37^{\circ} \mathrm{C}$ in a humidified incubator for $30 \mathrm{~min}$. Sperms moving at the edge of the HTF drop were collected and transferred to the new HTF drop containing MII oocytes. IVF was performed for $6 \mathrm{~h}$ under 5\% $\mathrm{CO}_{2}$ at $37^{\circ} \mathrm{C}$ in a humidified incubator. After IVF, zygotes were cultured to the blastocysts stage in KSOM under 5\% $\mathrm{CO}_{2}$ at $37^{\circ} \mathrm{C}$ in a humidified incubator (So et al., 2020).

\section{Preparation of recipients for embryo transfer}

For the conventional group, ICR female recipients were mated with vasectomized ICR mice overnight and checked for plug-in the following morning. For hormone groups, ICR female mice were injected 5 IU PMSG, followed by 5 IU hCG 48 h later. Depending on the experimental group, some hormone-injected ICR mice were mated with wild male ICR overnight and checked for plug-in the following morning.

\section{Embryo transfer}

Blastocysts were transferred into the uteri of ICR recipients. Pregnancy was estimated if recipients gained 2 or more grams one week after embryo transfer. The recipients were monitored for successful delivery and the number of pups was recorded after delivery.

\section{Statistical analyses}

Data are presented as means \pm standard error of the mean (s.e.m). ANOVA with Tukey analysis for multiple comparisons was used in this study. Statistical analyses were performed using GraphPad Prism software (version 5.02), with $p<0.05$ considered significant.

\section{RESULTS}

First, we investigated the pregnancy rates of 10 recipients in each group, each group showed a comparable rate without significance $(70 \% \pm 15 \%, 70 \% \pm 3 \%$, and $80 \% \pm$ $10 \%$ for the conventional, hormone, and hormone + pairing group, respectively, Table 1). Among pregnant recipients, a total of 5 among 7 recipients $(71 \% \pm 15 \%)$ were delivered in the conventional method group, while all recipients gave birth in hormone and hormone + pairing groups, but there was no significant difference among the groups (Table 1).

Next, we examined the birth rate by ET using recipient females prepared by different methods (Fig. 2A and B). Of the embryos transferred, $13 \%$ ( $n=15 / 118$ ) developed into full-term offspring in the conventional group. Hormone and hormone + pairing groups showed 19\% ( $\mathrm{n}=$ 18/96) and 33\% $(n=29 / 89)$ birth rates, respectively (Fig. 2A). Especially, the hormone + pairing group showed a significantly higher birth rate compared to the conventional group (Fig. 2A). In the hormone + pairing group, a total of 96 pups were delivered in 10 recipients. Among them, $30.2 \%(n=29)$ were derived from ET embryos (BDF2

Table 1. Pregnancy and delivery rates of ET recipients depending on the recipient preparation methods

\begin{tabular}{lccc}
\multicolumn{1}{c}{ Method } & Total recipients No. & Pregnancy No. (\%/total recipients) & Delivery No. (\%/pregnant recipients) \\
\hline Conventional & 10 & $7(70 \% \pm 15 \%)$ & $5(71 \% \pm 15 \%)$ \\
Hormone & 10 & $7(70 \% \pm 3 \%)$ & $7(100 \%)$ \\
Hormone + pairing & 10 & $8(80 \% \pm 10 \%)$ & $8(100 \%)$ \\
\hline
\end{tabular}

The data are presented by mean \pm s.e.m. There was no significant difference in pregnancy and delivery rate among the groups. 
A

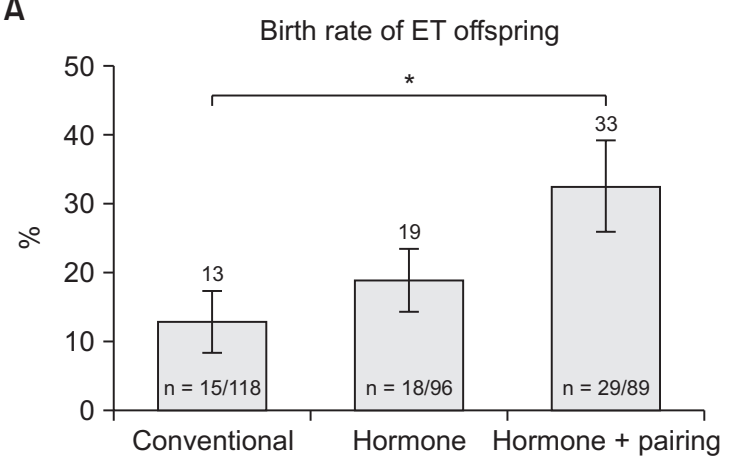

C hormone + pairing group

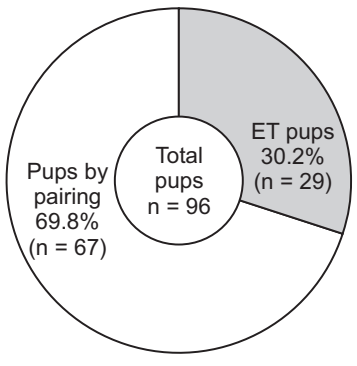

B

\begin{tabular}{|c|c|c|c|c|c|c|c|}
\hline Group & $\begin{array}{c}\text { Mouse } \\
\#\end{array}$ & $\begin{array}{c}\text { No. of } \\
\text { embryos } \\
\text { transferred }\end{array}$ & Pregnancy & Delivery & $\begin{array}{l}\text { No. of } \\
\text { ET pups } \\
\text { (BDF2) }\end{array}$ & $\begin{array}{c}\text { No. of pups } \\
\text { by paring } \\
\text { (ICR) }\end{array}$ & $\begin{array}{l}\text { No. of } \\
\text { total pups }\end{array}$ \\
\hline \multirow{11}{*}{ Conventianal } & 1 & 12 & $\bigcirc$ & $\bigcirc$ & 5 & - & 5 \\
\hline & 2 & 13 & $x$ & $x$ & 0 & - & 0 \\
\hline & 3 & 10 & 0 & $\times$ & 0 & - & 0 \\
\hline & 4 & 16 & $x$ & $x$ & 0 & - & 0 \\
\hline & 5 & 10 & 0 & $x$ & 0 & - & 0 \\
\hline & 6 & 9 & 0 & 0 & 3 & - & 3 \\
\hline & 8 & 12 & 0 & 0 & 3 & - & 3 \\
\hline & 7 & 17 & 0 & 0 & 3 & - & 3 \\
\hline & 9 & 9 & 0 & 0 & 1 & - & 1 \\
\hline & 10 & 10 & $\times$ & $x$ & 0 & - & 0 \\
\hline & Total & 118 & 7 & 5 & 15 & - & 15 \\
\hline \multirow{11}{*}{ Hormone } & 1 & 8 & 0 & 0 & 2 & - & 2 \\
\hline & 2 & 8 & 0 & 0 & 2 & - & 2 \\
\hline & 3 & 11 & 0 & 0 & 3 & - & 3 \\
\hline & 4 & 10 & $x$ & $x$ & 0 & - & 0 \\
\hline & 5 & 8 & 0 & 0 & 2 & - & 2 \\
\hline & 6 & 9 & $x$ & $x$ & 0 & - & 0 \\
\hline & 8 & 10 & 0 & 0 & 4 & - & 4 \\
\hline & 7 & 10 & 0 & 0 & 3 & - & 3 \\
\hline & 9 & 12 & 0 & 0 & 2 & - & 2 \\
\hline & 10 & 10 & $\times$ & $x$ & 0 & - & 0 \\
\hline & Total & 96 & 7 & 7 & 18 & - & 18 \\
\hline \multirow{11}{*}{$\begin{array}{l}\text { Hormone } \\
\text { +pairing }\end{array}$} & 1 & 8 & 0 & 0 & 3 & 7 & 10 \\
\hline & 2 & 14 & 0 & 0 & 5 & 9 & 14 \\
\hline & 3 & 11 & $\bigcirc$ & 0 & 3 & 10 & 13 \\
\hline & 4 & 8 & $x$ & $x$ & 0 & 0 & 0 \\
\hline & 8 & 8 & 0 & 0 & 4 & 8 & 12 \\
\hline & 6 & 7 & 0 & 0 & 4 & 10 & 14 \\
\hline & 7 & 7 & 0 & 0 & 4 & 7 & 11 \\
\hline & 5 & 10 & $\times$ & $x$ & 0 & 0 & 0 \\
\hline & 9 & 8 & 0 & 0 & 2 & 8 & 10 \\
\hline & 10 & 8 & 0 & 0 & 4 & 8 & 12 \\
\hline & Total & 89 & 8 & 8 & 29 & 67 & 96 \\
\hline
\end{tabular}

Fig. 2. Reproductive performance depends on different protocols of recipients' preparation. (A) The birth rate of ET offspring. The hormone + pairing group showed a significantly higher birth rate compared to the conventional group $\left({ }^{*} p<0.05\right)$. n means the number of offspring/the number of transferred embryos. mean \pm s.e.m. (B) The reproductive data after ET. (C) The birth ratio between ET pups and pups by natural paring in the hormone + pairing group. 30.2\% ( $n=29)$ were derived from ET embryos (BDF2 embryos) among a total of 96 pups. (D) The ET pup number of litters. The average number of litters was comparable among the groups. $\mathrm{n}$. $\mathrm{s}$ means no significant difference. mean \pm s.e.m.

embryos) and $69.8 \%(n=69)$ were originated from nature paring (ICR embryos) (Fig. 2C). The average number of litters of the conventional and hormone group were $3 \pm$ 0.6 and $2.6 \pm 0.3$, respectively (Fig. 2D). In the hormone + pairing group, the average number of litters was $9.6 \pm$ 1.7, which included all pups originating from ET and natural paring. The number of litters generated by ET was 3.6 \pm 0.3 in the hormone + pairing group. All groups showed comparable numbers of ET litters (Fig. 2D).

Based on the results, our new methods of recipient preparation using hormone injection tended to increase the delivery rate, and natural pregnancy of hormone-injected recipients improved the efficiency of ET offspring generation.

\section{DISCUSSION}

The present study demonstrated whether recipients injected hormone and pairing with males could be efficient to produce ET offspring than pseudopregnancy. For this purpose, we attempted to synchronize the estrous cycle of recipients using hormones and mate recipients with wild male mice. As a result, a new method of recipient preparation tended to increase the delivery rate and improve the birth rate of ET offspring compared to the conventional one.

Previous studies reported that hCG treatment caused a significant decrease in birth rates after ET because of an unbalanced endocrinological environment of the uterine epithelium (Ezoe et al., 2014; Hasegawa et al., 2017). The current study also used hCG, however, the delivery rate of recipients tended to be increased and the birth rate was significantly enhanced. Even though previous studies and our study both used hCG, but hormones other than hCG and injection schedules were different, which induced different results regarding ET efficiency.

Most studies used vasectomized males to induce pseudopregnant recipients. Male sterile genetically modified 
mouse lines could be also used to generate pseudopregnant recipients, which were generated by the mating of two wild-type laboratory strains, such as PWDB6F1 hybrids, generated by crosses between male C57BL/6J and female $\mathrm{PWD} / \mathrm{PhJ}$ mice, or hybrids between $\mathrm{C} 57 \mathrm{BL} / 6 \mathrm{~J}$ and STUS/Fore parental strains in both directions (Gregorová and Forejt, 2000; Flachs et al., 2012). While we used wild ICR males to induce natural pregnancy in ET recipients, which was more convenient and simpler compared to the preparation of vasectomized or genetically modified mice. We supposed that natural pregnancy could be efficient rather than pseudo-pregnancy to produce ET offspring because it could help to make the appropriate intrauterine environment for implantation of ET embryos and maintenance of pregnancy for ET pups. When ET offspring, especially for producing transgenic mice, could be retrieved by Caesarean section, the pregnant females should be prepared as foster mothers for successful nursing. However, if ET recipients are able to deliver naturally pregnant pups, the success rate of delivery could be enhanced, and the preparation of foster mothers can be skipped.

Finally, hormone injection for estrous synchronization of ET recipients could help to reduce the size of female colonies and improve recipient welfare through the use of fewer numbers of mice in the experiment.

\section{CONCLUSION}

Based on the results, the new protocol of ET recipient preparation using hormones tended to increase the delivery rate. Further, the natural pregnancy of the recipients enhanced the birth rate of ET offspring. Therefore, we concluded our new protocol using hormone injection to recipients and mating with wild male mice could be efficient and simple compared to the conventional method.

Author Contributions: Conceptualization, Y.L., E.K.; data curation, Y.L., E.K.; formal analysis, Y.L., E.K.; funding acquisition, Y.L., E.K.; investigation, Y.L., E.K.; methodology, Y.L., E.K.; project administration, Y.L., E.K.; resources, Y.L., E.K.; software, Y.L., E.K.; supervision, E.K.; validation, Y.L., E.K.; visualization, Y.L., E.K.; writing - original draft, Y.L.; writing - review \& editing, Y.L., E.K.

Funding: This work has been supported by the $\mathrm{Na}-$ tional Research Foundation of Korea (grant nos. NRF2018R1A2B3001244 and NRF-2021R1I1A1A01049705) and an intramural grant from the CHA University (202100320001).

Ethical Approval: This study was approved by the Institutional Animal Care and Use Committee of CHA University (IACUC No.210035).

Consent to Participate: Not applicable.

Consent to Publish: Not applicable.

Availability of Data and Materials: Not applicable.

Acknowledgements: None.

Conflicts of Interest: No potential conflict of interest relevant to this article was reported.

\section{REFERENCES}

Barsuren E, Kim SH, Lee HJ, Yoon JT. 2019. Effect of embryo transfer seven days after artificial insemination with sexed and conventional semen from superovulated cattle. J. Anim. Reprod. Biotechnol. 34:106-110.

Bradford GE. 1979. Genetic variation in prenatal survival and litter size. J. Anim. Sci. 49 Suppl 2:66-74.

Byers SL, Wiles MV, Dunn SL, Taft RA. 2012. Mouse estrous cycle identification tool and images. PLoS One 7:e35538.

Choi BH, Park BY, Kong R, Son MJ, Park CS, Shin NH, Cheon HY, Yang YR, Lee JW, Jin JI, Kong IK. 2019. Effect of serum and serum free media on the developmental competence of OPU derived bovine IVP embryo. J. Anim. Reprod. Biotechnol. 34:305-310.

Ertzeid G and Storeng R. 2001. The impact of ovarian stimulation on implantation and fetal development in mice. Hum. Reprod. 16:221-225.

Ezoe K, Daikoku T, Yabuuchi A, Murata N, Kawano H, Abe T, Okuno T, Kobayashi T, Kato K. 2014. Ovarian stimulation using human chorionic gonadotrophin impairs blastocyst implantation and decidualization by altering ovarian hormone levels and downstream signaling in mice. Mol. Hum. Reprod. 20:1101-1116.

Flachs P, Mihola O, Simeček P, Gregorová S, Schimenti JC, Matsui Y, Baudat F, de Massy B, Piálek J, Forejt J, Trachtulec Z. 2012. Interallelic and intergenic incompatibilities of the Prdm9 (Hstl) gene in mouse hybrid sterility. PLoS Genet. 8:e1003044.

Gregorová S and Forejt J. 2000. PWD/Ph and PWK/Ph inbred 
mouse strains of Mus m. musculus subspecies--a valuable resource of phenotypic variations and genomic polymorphisms. Folia Biol. (Praha) 46:31-41.

Ha AN, Fakruzzaman M, Lee KL, Wang E, Lee JI, Min CS, Kong IK. 2013. Development of new vitrification method for preimplantation mouse embryo. J. Emb. Trans. 28:141-147.

Hasegawa A, Mochida K, Ogonuki N, Hirose M, Tomishima T, Inoue K, Ogura A. 2017. Efficient and scheduled production of pseudopregnant female mice for embryo transfer by estrous cycle synchronization. J. Reprod. Dev. 63:539-545.

Jung NH, Kim SH, Kim DS, Yoon JT. 2020. Study on the in-vitro culture method for normal embryonic cell development of porcine parthenogenetic embryos. J. Anim. Reprod. Biotechnol. 35:94-101.

Kim SG and Park HD. 2019. Effect of addition of ESCM and ESM during in vitro maturation on in vitro development of porcine follicular oocytes. J. Anim. Reprod. Biotechnol. 34:205211.

Lamas S, Franquinho F, Morgado M, Mesquita JR, Gärtner F, Amorim I. 2020. C57BL/6J and B6129F1 embryo transfer: unilateral and bilateral transfer, embryo number and recipi- ent female background control for the optimization of embryo survival and litter size. Animals (Basel) 10:1424.

Lee M, Ahn JI, Kwun H, Ko DW, Ahn J, Lim JM. 2018. Possible improvement of oocyte supply by the use of aged mice and different gonadotrophins. J. Emb. Trans. 33:69-73.

Lee SJ, Bae HS, Koo OJ. 2015. Optimization of in vitro murine embryo culture condition based on commercial M16 media. J. Emb. Trans. 30:315-317.

Mahabir E, Volland R, Landsberger A, Manz S, Na E, Urban I, Michel G. 2018. Reproductive performance after unilateral or bilateral oviduct transfer of 2-cell embryos in mice. J. Am. Assoc. Lab. Anim. Sci. 57:110-114.

Mochida K. 2020. Development of assisted reproductive technologies in small animal species for their efficient preservation and production. J. Reprod. Dev. 66:299-306.

Preece C, Alghadban S, Bouchareb A, Moralli D, Biggs D, Davies B. 2021. Replacement of surgical vasectomy through the use of wild-type sterile hybrids. Lab Anim. (NY.) 50:49-52.

So S, Karagozlu MZ, Lee Y, Kang E. 2020. Fasudil increases the establishment of somatic cell nuclear transfer embryonic stem cells in mouse. J. Anim. Reprod. Biotechnol. 35:21-27. 